\title{
Intoxicación por Sales de Hierro como gesto autolítico
}

\author{
Miguel Ángel Martínez Sánchez ${ }^{\mathrm{a}}$, Rosa Roldán Ortega ${ }^{\mathrm{b}}$, Raquel Pardo Blázquez
}

\begin{abstract}
a Residente de Medicina Familiar y Comunitaria, Unidad Docente de Albacete-Hellín.

\section{${ }^{\mathrm{b}}$ Especialista en Medicina Familiar y Comunitaria, Medico de Urgencias Hospitalarias, Hospital de Hellín (Albacete).}

Correspondencia: Miguel Ángel Martínez Sánchez, $\mathrm{C} /$ Las Eras $\mathrm{n}^{\circ} 134,1^{\circ} \mathrm{C}$, 02660-Caudete (Albacete), España. Telf.: 654491592 , e-mail: mianmar80@gmail.com.

Recibido el 22 de marzo de 2009.

Aceptado para su publicación el 25 de abril de 2009.

\begin{abstract}
RESUMEN
La intoxicación por hierro puede causar un fracaso multiorgánico que puede llevar a la muerte. Se presenta el caso de un paciente de 21 años que consultó en la unidad de urgencias tras ingerir, con ánimo autolítico, $2.100 \mathrm{mg}$ de hierro elemento. Refirió una sintomatología inicial compatible con gastritis. Se constató la presencia de comprimidos radio-opacos en una radiografía simple de abdomen. La concentración de hierro en la sangre se mantuvo aumentada durante las primeras 48 horas, por lo que precisó terapia con deferoxamina.

Se revisa el mecanismo fisiopatológico, las manifestaciones clínicas y el tratamiento de la intoxicación por hierro.

Palabras clave. Sobredosis, Sales de Hierro.
\end{abstract}

\section{ABSTRACT}

Iron salts overdose as a suicide attempt

Taking an overdose of iron may cause multi-organ failure that can lead to death. We present a case of a 21-yerars old patient, who went to a hospital emergency department after a suicide attempt. He said he had swallowed $2100 \mathrm{mg}$ of iron salts. He complained of some non-specific gastrointestinal symptoms such as stomach-ache. The presence of radio-opaque pills was observed in an abdominal X-ray. His serum iron concentration remained high for 48 hours, requiring deferoxamine treatment. After an observation period he was asymptomatic and is transferred to to a hospital ward. We review the physiopathology, clinical manifestation and treatment of iron poisoning.

Key words. Overdose, Iron Salts.

\section{INTRODUCCIÓN}

El hierro es un elemento esencial para diversas funciones vitales del organismo, sin embargo, a altas dosis se convierte en una sustancia tóxica que puede producir la muerte. Habitualmente en medicina se usan preparados de sulfato ferroso que equivalen a una dosis diaria de aproximadamente 100-200 mg de hierro elemento al día.

\section{OBSERVACIONES CLÍNICAS}

Paciente varón de 21 años de origen Boliviano que reside en España desde hace aproximadamente 3 años y con antecedentes de consumo de cocaína por vía intranasal, que actualmente niega. El paciente acudió a la Unidad de Urgencias del Hospital de Hellín por iniciativa propia tras la ingesta de 20 comprimidos de sulfato ferroso junto con 30 cápsulas de metamizol magnésico, equivalentes a $2.100 \mathrm{mg}$ de hierro elemento (aprox. $30 \mathrm{mg} / \mathrm{kg}$ ) y 17,25 gramos de metamizol.

En el momento de admisión el paciente se encontraba consciente y orientado, con quejas de dolor epigástrico, sin vómitos ni nauseas. La presión arterial era de 116/74 $\mathrm{mmHg}$, la frecuencia cardiaca de 80 latidos por minuto y la temperatura axilar de $35^{\prime} 8^{\circ} \mathrm{C}$. La exploración neurológica y cardio-respiratoria era normal. El abdomen blando y depresible, con dolor a la palpación epigástrica y con peristaltismo conservado. Tras la primera valoración, se inició lavado gástrico con suero bicarbonatado a dosis de $50 \mathrm{mEq}$ de bicarbonato $1 \mathrm{M}$ por cada $1000 \mathrm{ml}$ de suero fisiológico.

Entre las exploraciones complementarias realizadas se constató un hematocrito del $40,7 \%$, hemoglobina de $13,7 \mathrm{~g} / \mathrm{L}, 226.000$ plaquetas $/ \mathrm{mm}^{3}$ y 8.820 leucocitos $/ \mathrm{mm}^{3}$, 
con un $75^{\prime} 1 \%$ de neutrófilos. Otros parámetros: glucemia $96 \mathrm{mg} / \mathrm{dl}$, creatinina 0'4 mg/dL, sodio $141 \mathrm{mEq} /$ $\mathrm{L}$ y potasio 3'4 mEq/L. Una radiografía de abdomen puso de manifiesto unos 10 comprimidos radio-opacos en la luz intestinal. Ante el deterioro del estado general del paciente, se solicitó gasometría arterial, con $\mathrm{pH}$ 7'33, pCO2 39'5 mmHg, pO2 58'20 mmHg, bicarbonato $20^{\prime} 7 \mathrm{mmol} / \mathrm{L}$, y sideremia a las 5 horas de la ingesta con valores de $349 \mathrm{mcg} / \mathrm{dl}$ (valores normales $60-160 \mathrm{mcg} / \mathrm{dL}$ ). Se decidió realizar tratamiento quelante con $1 \mathrm{~g}$ de deferoxamina y diuresis alcalina

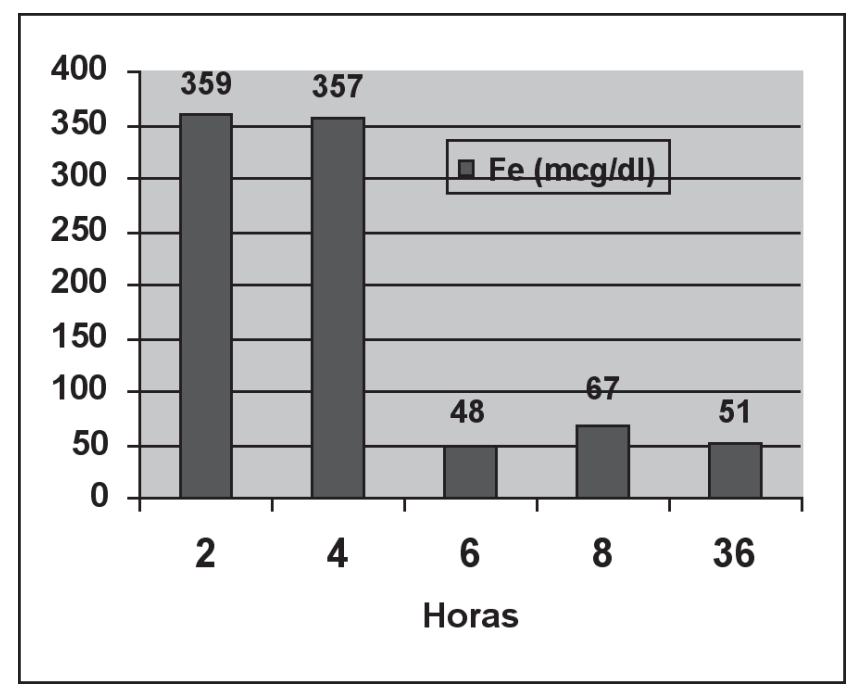

Figura 1. Evolución de la sideremia. A las 5 horas de la ingesta se inició tratamiento quelante.

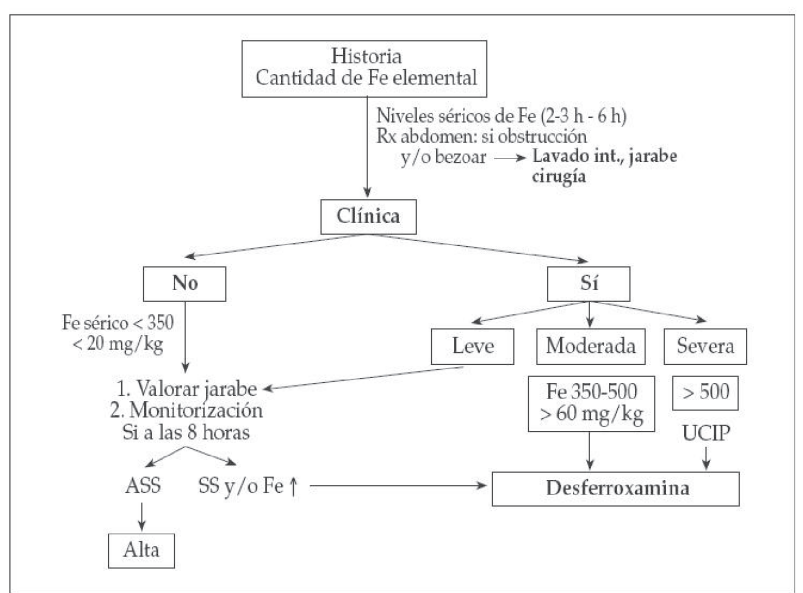

Figura 3. Algoritmo terapéutico (ASS: asintomático; SS: sintomático). Tomado de: Diez Sáez C, Esteban López S, Ayala Curial M. Intoxicaciones por hierro y otros metales. En: Grupo de trabajo de Intoxicaciones de la Sociedad Española de Urgencias en Pediatria, editores. Manual de Intoxicaciones en Pediatria. $2^{\mathrm{a}}$ ed. Madrid: Ergón; 2008. p. 269-80.

forzada, evidenciándose mejoría clínica y analítica (figura 1).

El paciente se mantuvo en observación durante 36 horas hasta el control de los niveles de sideremia y del equilibrio ácido-base. Posteriormente fue ingresado durante tres días en el Servicio de Medicina Interna de nuestro Hospital. Durante todo el tiempo permaneció asintomático y estable hemodinámicante, por lo que se decidió control ambulatorio.
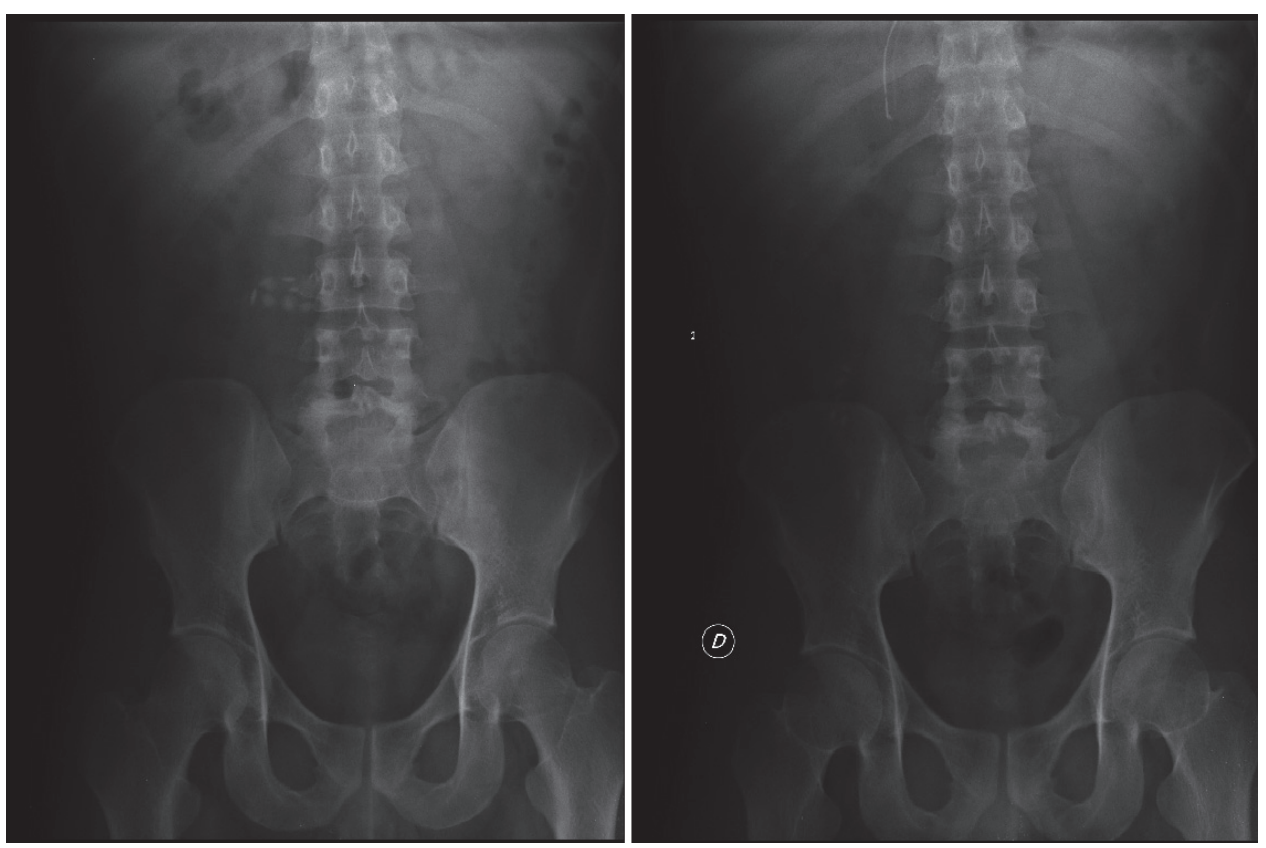

Figura 2. Radiología simple como exploración complementaria para la cuantificación de la ingesta y la valoración de la eficacia del tratamiento. 


\section{COMENTARIOS}

El hierro se absorbe en forma ferrosa en el duodeno y yeyuno proximal, a través de sistemas de transporte activo, tratándose de procesos saturables (el porcentaje de absorción se encuentre entre el 10 y el 35 $\%$ de la dosis ingerida). Una vez el hierro está en las células de la mucosa intestinal, se convierte en forma férrica para unirse a la transferrina, que es la principal proteína encargada del transporte del hierro. Existen otras proteínas plasmáticas, como la albúmina, que se unen con menor afinidad al hierro, tratando de mitigar el daño que produce el hierro libre, ya que éste reacciona con el agua para formar hidróxido de hierro y liberar hidrogeniones que acidifican el medio interno. A dosis tóxicas, los sistemas buffer no alcanzan a controlar el equilibrio ácido-básico que se puede presentar en casos de sobredosis, apareciendo una acidosis metabólica. Se considera que la dosis tóxica del hierro por vía oral es de $20 \mathrm{mg} / \mathrm{kg}$ (en el caso clínico que se presenta la dosis ingerida fue de $30 \mathrm{mg} / \mathrm{kg}$, es decir, una dosis tóxica).

Las manifestaciones clínicas se han dividido clásicamente en tres estadios. El primero de ellos es gastrointestinal y es el más precoz: se presenta en las 6 primeras horas en forma de vómitos, dolor abdominal, diarreas, hematemesis o hematoquecias, variando la presentación desde síntomas leves a graves. La segunda fase es asintomática y puede durar entre 624 horas. La tercera fase es la de mayor riesgo de mortalidad y pude presentarse entre las 6 y 72 horas después de la ingesta, en forma de shock. La acidosis que se presenta en esta fase puede explicarse tanto por el shock como por la formación de hidrogeniones, que se generan cuando el hierro férrico se hidrata, como se mencionó anteriormente. Algunos autores consideran una cuarta fase, en los días sucesivos, en la que se produce una hepatotoxicidad que puede provocar la muerte, y también una quinta fase, en las siguientes semanas, en las cuales se forman estenosis y obstrucciones del tubo digestivo secundarías a las lesiones ocasionadas en la fase aguda.

La radiografía simple de abdomen es una exploración complementaria que tiene un particular interés en la primera fase de la intoxicación, ya que al ser el hierro radio-opaco, permite calcular aproximadamente la dosis ingerida y la eficacia de las medidas empleadas para descontaminar el tubo digestivo (Figura 2).

El tratamiento específico de la intoxicación por hierro es la deferoxamina. La deferoxamina se indica en presencia de acidosis metabólica, mal estado general, letargia, hipotensión y en todo paciente que tenga niveles de hierro superiores a $500 \mathrm{mcg} / \mathrm{dL}$. La deferoxamina parenteral consigue eliminar $9 \mathrm{mcg}$ de hierro libre por cada $100 \mathrm{mg}$ de deferoxamina administrados. Una vez lograda la quelación deferoxamina-hierro, el complejo se excretará por la orina dándole un color de vino rosado, pero este fenómeno no es un indicador fiable de la eliminación del hierro. Durante el tratamiento se monitorizan los niveles de hierro y, si éstos bajan de $100 \mathrm{mcg} / \mathrm{dl}$ o la orina se torna clara y el paciente está asintomático, se puede suspender el tratamiento sin tener que llegar a la máxima dosis recomendada.

En conclusión, la intoxicación por hierro es un evento potencialmente grave y poco usual, en el que si no se toman medidas de forma inmediata puede ocasionar la muerte del paciente.

\section{BIBLIOGRAFÍA}

- Aroyave C, Salvador E, Nogué S, Munné P. Intoxicación por sales de hierro en un embarazada. Rev Toxicol 2005; 22:41-3.

- Diez Sáez C, Esteban López S, Ayala Curial M. Intoxicaciones por hierro y otros metales. En: Grupo de trabajo de Intoxicaciones de la Sociedad Española de Urgencias en Pediatria, editores. Manual de Intoxicaciones en Pediatria. $2^{\mathrm{a}}$ ed. Madrid: Ergón; 2008. p. 269-80.

- Heras Ballesteros MC, García Marfil MI, García González F. Quelantes del hierro: situación actual y perspectivas terapéuticas. Farm Hosp 1995; 19:323-9.

- Laín Teres N. Intoxicación. Medidas específicas. En: Manual de Actuación y Protocolos en Urgencias. Toledo: FISCAM; 2007. 